\title{
Exigência de proteína de alevinos de piavuçú
}

\author{
Requirement of protein for piavuçu fry
}

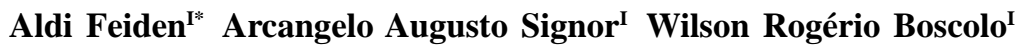 \\ Altevir Signor ${ }^{\mathrm{II}}$ Adilson Reidel ${ }^{\mathrm{II}}$
}

\section{RESUMO}

O piavuçu Leporinus macrocephalus apresenta hábito alimentar onívoro, alimentando-se de vegetais e sementes. Os alimentos protéicos apresentam maior custo se comparados aos alimentos energéticos. Portanto, quanto maior o teor de proteína nas rações, maior pode ser o custo de produção dos peixes. O presente trabalho objetivou avaliar a exigência de proteína bruta na dieta de alevinos de piavuçu (L. macrocephalus). Foram distribuídos em um delineamento inteiramente casualizado 125 alevinos $(0,625 \pm 0,011 \mathrm{~g})$, em 25 aquários de 301 , constituindo cinco tratamentos e cinco repetições. As dietas foram formuladas de forma a conter 22 , 26, 30, 34 e 38\% de proteína bruta e 3200kcal ED kg-1. Os peixes foram alimentados quatro vezes ao dia $(8 \mathrm{~h}, 11 \mathrm{~h}, 14 \mathrm{~h}$ e 17h). Os parâmetros de qualidade de água durante o período experimental permaneceram dentro das condições normais para o bom desempenho dos animais. Os melhores resultados de peso final, ganho de peso e conversão alimentar aparente foram observados para os peixes alimentados com rações contendo 34 e $38 \%$ de $P B$, diferindo $(P<0,05)$ dos tratamentos com 22, 26 e 30\% de PB. Também não ocorreu variação na deposição protéica e na taxa de eficiência protéica na carcaça dos animais. Recomenda-se a utilização de $34 \%$ de proteína bruta na dieta de alevinos de piavuçu (L. macrocephalus).

Palavras-chave: alevinos, exigência nutricional, nutrição de peixes, piscicultura.

\section{ABSTRACT}

The piavuçu Leporinus macrocephalus presents omnivore feeding habits, eating vegetables and seeds. The protein feed presents higher cost compared to energetic feed. Therefore, the higher protein content is in the ration, the higher might be the production cost of the fish. This study aimed to evaluate the gross protein need in the diet of piavuçu fingerlings (L. macrocephalus). 125 fingerlings $(0.625 \pm 0.011 \mathrm{~g})$ were distributed into 25 aquariums with a $30 \mathrm{~L}$ capacity at a random design, with five treatments and five repetitions. The diets were formulated to contain 22; 26; 30; 34 and 38\% of gross protein and $3200 \mathrm{kcal} \mathrm{DeE} \mathrm{kg.}^{-1}$ The fish were fed four times a day (8:00am; 11:00am; 2:00pm; and 5:00pm). The water quality parameters during the experimental period remained in the normal conditions for good animal development. The best results of the final weight, gain weight and apparent feeding conversion were observed for fishes which were fed with diets containing 34 and 38\% of gross protein, having differences $(P<0.05)$ on the treatments with 22, 26 and 30 of $P B$. Also there was no variation in the protein deposition and protein efficiency rate in the animals' carcass. It is recommended to use $34 \%$ of protein gross on the diets of piavuçu fingerlings.

Key words: fry, nutritional demand, fish nutrition, fish culture.

\section{INTRODUÇÃO}

O piavuçu Leporinus macrocephalus apresenta hábito alimentar onívoro, consumindo ampla variedade de alimentos, sendo que os vegetais e as sementes são itens freqüentes em sua dieta. Esta espécie tem grande potencial para a piscicultura, pois apresenta excelente desempenho produtivo e elevado crescimento inicial, rusticidade ao manejo e resistência a doenças, quando alimentados com dietas práticas (SOARES et al., 2000; BOSCOLO et al., 2005). Entretanto, são poucas as pesquisas sobre suas exigências nutricionais (BOSCOLO et al., 2005).

IPrograma de Pós-graduação em Zootecnia, Universidade Estadual do Oeste do Paraná (UNIOESTE), Toledo, PR, Brasil.

IIPrograma de Pós-graduação em Zootecnia, Universidade Estadual Paulista (UNESP), Botucatu, SP, Brasil.

IIInstituto Federal de Educação, Ciência e Tecnologia do Paraná (IFET-PR), Paranaguá, PR, Brasil. E-mail: aldi@unioeste.br.

*Autor para correspondência. 
As dietas utilizadas nos sistemas de cultivo intensivo e super-intensivo de peixes podem atingir custos de produção superiores a 50\% (EL-SAYED, 1999), principalmente pela alta inclusão de ingredientes protéicos na formulação de rações (BOSCOLO et al., 2005). A proteína é o nutriente de máxima importância para o animal em crescimento. Os teores adequados de proteína e do perfil de aminoácidos na dieta proporcionam a melhor utilização dos nutrientes e conseqüentemente o melhor desempenho aos peixes (HAYASHI et al., 2002; FURUYA et al., 2004).

As principais funções metabólicas dos aminoácidos são manutenção e formação dos tecidos, dos hormônios, das enzimas e dos anticorpos. Também atuam no transporte de minerais utilizados na síntese protéica e/ou em compostos nitrogenados essenciais para o metabolismo durante o processo de crescimento e o processo de reprodução, ou ainda podem ser utilizados como fonte de energia (MILLWARD, 1989; LENHINGER et al., 1995). Dietas deficientes em aminoácidos podem causar redução no crescimento, menor eficiência alimentar ou ainda imunodepressão e provocam alterações metabólicas prejudiciais (MEIJER et al., 1990). Entretanto, em uma dieta com excesso de proteína além do necessário para a formação de tecido muscular e o crescimento, os aminoácidos em excesso serão convertidos em energia ou em gordura (MILLWARD, 1989) e os resíduos nitrogenados serão excretados na forma de amônia, resultando em maior poluição ambiental.

O teor de proteína dietética exigida para todas as fases do crescimento dos animais é complexo porque ocorre influência de inúmeros fatores (BROWN \& ROBINSON, 1989), entre eles, a temperatura da água, o tamanho do peixe, as formas de arraçoamento, a qualidade da proteína utilizada, a participação de fontes energéticas não-protéicas, os suplementos vitamínicos e/ou minerais, a utilização de produtos funcionais (ROBINSON \& WILSON, 1985) e a relação proteína/ energia na dieta (SILVA \& ANDERSON, 1995), além da disponibilidade dos nutrientes dos ingredientes aos animais. Portanto, é de fundamental importância determinar a exigência protéica dos peixes para cada fase de criação, fornecendo níveis adequados deste nutriente (FURUYA et al., 1996), reduzindo os custos de produção e diminuindo a excreção principalmente de nitrogênio ao ambiente aquático (GONÇALVES \& FURUYA, 2004). Neste sentido, o presente trabalho teve por objetivo avaliar a exigência de proteína bruta na dieta de alevinos de piavuçú (L. macrocephalus).

\section{MATERIAL E MÉTODOS}

O experimento foi realizado por um período de 32 dias no Laboratório de Aqüicultura da Universidade Estadual do Oeste do Paraná, campus de Toledo. Foram distribuídos em um delineamento inteiramente casualizado 125 alevinos de piavuçú com peso inicial médio de 0,625士0,011g, em 25 aquários de 30l, constituindo cinco tratamentos e cinco repetições. Os aquários experimentais apresentaram aeração e renovação diária de $40 \%$ da água, realizada após a sifonagem dos aquários para remoção das fezes e das sobras de rações, no período da manhã e da tarde antes da primeira e da última alimentação. Os parâmetros físico-químicos da água, como oxigênio dissolvido (mg $\left.\mathrm{L}^{-1}\right)$, $\mathrm{pH}$ e condutividade elétrica $\left(\mu \mathrm{S} \mathrm{cm}^{-1}\right)$, foram mensurados semanalmente e a temperatura $\left({ }^{\circ} \mathrm{C}\right)$ foi monitorada diariamente.

As rações foram formuladas (Tabela 1) de maneira a conter 22, 26, 30, 34 e 38\% de proteína bruta, sendo as mesmas isoenergéticas (3200kcal ED kg-1). Para a confecção das rações, os ingredientes foram moídos em moinho tipo faca com peneira de $0,5 \mathrm{~mm}$. Posteriormente, as rações foram homogeneizadas, peletizadas e secas em estufa com ventilação forçada.

$\mathrm{O}$ arraçoamento foi realizado quatro vezes ao dia (8h, 11h, 14h e 17h), na proporção de $10 \%$ do peso vivo. Para a manutenção da percentagem de arraçoamento, foi realizada uma biometria quinzenal para aferição da quantidade de ração a ser fornecida. Ainda para correção parcial do arraçoamento houve um acréscimo de $5 \%$ na ração sobre o peso da última biometria, operação realizada a cada três dias.

Ao final do experimento, os peixes de cada unidade experimental foram submetidos a $12 \mathrm{~h}$ de jejum para o esvaziamento do trato digestório, sendo que posteriormente eles foram contados, pesados e medidos para o cálculo das médias de ganho de peso (GP), conversão alimentar aparente (CA) e sobrevivência (SO). Todos os animais foram congelados para análises posteriores da composição química dos peixes inteiros (proteína, umidade e matéria seca), segundo metodologia descrita na ASSOCIATION OF OFFICIAL ANALYTICAL CHEMISTS (2000). Também foi realizado o cálculo da taxa de eficiência protéica (ganho de peso/consumo de proteína).

Os dados obtidos foram submetidos à análise de variância ao nível de 5\% de significância e em caso de diferença foi aplicado o teste de Scott Knott, e também foi realizada a análise de regressão pelo Programa Estatístico Computacional SAEG(UFV, 1997). 
Tabela 1 - Composição percentual e composição química das rações experimentais com diferentes níveis de proteína bruta para alevinos piavuçu (L. macrocephalus) (matéria natural).

\begin{tabular}{|c|c|c|c|c|c|}
\hline \multirow{2}{*}{ Alimentos (\%) } & \multicolumn{5}{|c|}{ 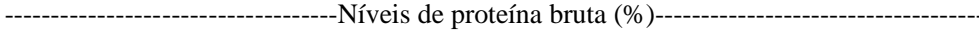 } \\
\hline & 22 & 26 & 30 & 34 & 38 \\
\hline Fosfato bicálcico & 1,007 & 0,755 & 0,503 & 0,251 & 0,000 \\
\hline Farelo de soja & 21,097 & 30,614 & 40,131 & 49,648 & 59,167 \\
\hline Farinha de resíduos de tilápias & 15,319 & 15,796 & 16,273 & 16,750 & 17,228 \\
\hline Milho & 58,912 & 49,412 & 39,912 & 30,412 & 20,910 \\
\hline Óleo de soja & 2,165 & 1,920 & 1,679 & 1,436 & 1,194 \\
\hline Suplemento (min. vit.) $^{1}$ & 1,000 & 1,000 & 1,000 & 1,000 & 1,000 \\
\hline Sal & 0,500 & 0,500 & 0,500 & 0,500 & 0,500 \\
\hline Total & 100 & 100 & 100 & 100 & 100 \\
\hline \multicolumn{6}{|l|}{ Nutriente $^{2} \%$} \\
\hline Amido & 39,550 & 34,916 & 30,282 & 25,648 & 21,015 \\
\hline Cálcio & 1,500 & 1,500 & 1,500 & 1,500 & 1,500 \\
\hline Energia digestível $^{3}$ & 3200 & 3200 & 3200 & 3200 & 3200 \\
\hline Fibra & 2,380 & 2,761 & 3,142 & 3,523 & 3,904 \\
\hline Fósforo total & 0,878 & 0,878 & 0,878 & 0,878 & 0,878 \\
\hline Gordura & 7,808 & 7,474 & 7,140 & 6,806 & 6,473 \\
\hline Linoléico & 2,458 & 2,2145 & 1,971 & 1,7275 & 1,484 \\
\hline Lisina & 1,316 & 1,575 & 1,834 & 2,093 & 2,352 \\
\hline Cistina & 0,562 & 0,606 & 0,649 & 0,692 & 0,736 \\
\hline Metionina & 0,478 & 0,531 & 0,584 & 0,638 & 0,691 \\
\hline Relação ED/PB (kcal g ${ }^{-1}$ ) & 14,545 & 12,308 & 10,667 & 9,412 & 8,421 \\
\hline
\end{tabular}

${ }^{1}$ Níveis de garantia por quilograma do produto: Vit. A, 500.000UI; Vit. $\mathrm{D}_{3}$, 200.000UI; Vit. E, 5.000mg; Vit. K3, 1.000mg; Vit. B1, 1.500mg; Vit. B2, 1.500mg; Vit. B6, 1.500mg; Vit. B12, 4.000mg; Ác. Fólico, 500mg; Pantotenato Ca, 4.000mg; Vit. C, 15.000mg; Biotina, 50mg; Inositol, 10.000; Nicotinamida, 7.000; Colina, 40.000mg; Co, 10mg; Cu, 500mg; Fe, 5.000mg; I, 50mg; Mn, 1500mg; Se, 10mg; Zn, $5.000 \mathrm{mg}$.

${ }^{2}$ Exigência nutricional baseada no NRC (1993).

${ }^{3}$ Baseados no valor de energia digestível propostos por BOSCOLO et al. (2002).

\section{RESULTADOS E DISCUSSÕES}

Os valores médios dos parâmetros físicoquímicos como temperatura, $\mathrm{pH}$, condutividade elétrica e oxigênio dissolvido permaneceram dentro dos valores recomendados para peixes de clima tropical (BOYD, 1990), com médias de $27,30 \pm 0,66^{\circ} \mathrm{C} ; 7,61 \pm 0,32$; $92,32 \pm 1,70 \mu \mathrm{S} \mathrm{cm}^{-1} ; 6,02 \pm 0,45 \mathrm{mg} \mathrm{L}^{-1}$, respectivamente. Os valores médios de ganho de peso, comprimento final, conversão alimentar aparente e sobrevivência avaliados neste experimento estão apresentados na tabela 2.

Os melhores valores médios de peso final e ganho de peso foram observados para os peixes alimentados com rações contendo 34 e 38\% de proteína bruta, diferindo $(\mathrm{P}<0,05)$ dos peixes alimentados com 22, 26 e 30\% de proteína bruta. Estes resultados demonstram que os níveis inferiores não atendem a exigência dos animais. Portanto, a exigência de nutrientes para o seu máximo crescimento é atingida com o mínimo de 34\% de proteína bruta nas rações.
Estes resultados são semelhantes aos observados por SÁ e FRACALOSSI (2002) para alevinos de piracanjuba (Brycon orbignyanus), os quais relatam que o melhor peso final e o melhor ganho de peso foram observados nos peixes alimentados com rações contendo $29 \%$ de proteína bruta e relatam que os incrementos superiores de proteína bruta não produziam melhoras nestes índices. Efeitos quadráticos para o ganho de peso foram observados por FURUYA et al. (2000), avaliando a eficiência protéica na dieta de alevinos de tilápia do Nilo (Oreochromis niloticus), nos níveis de 24, 26, 28, 30, 32, 34 e 36\% e 2835kcal energia digestível $\mathrm{kg}^{-1}$. Estes autores observaram resultados melhores para os animais alimentados com 32\% de proteína bruta, sendo que os níveis superiores causaram prejuízo no desempenho dos animais.

Foi observado melhor índice de conversão alimentar para os peixes alimentados com 34 e 38\% de proteína bruta nas rações. Por outro lado, os peixes alimentados com rações contendo 22, 26 e 30\% de proteína bruta apresentaram o pior índice de conversão 
Tabela 2 - Desempenho de alevinos de piavuçu (L. macrocephalus) alimentados com dietas contendo diferentes níveis de proteína bruta.

\begin{tabular}{|c|c|c|c|c|c|c|}
\hline \multirow{2}{*}{ Parâmetros } & \multicolumn{5}{|c|}{------------------------------Níveis de proteína bruta (\%)------------------------------ } & \multirow{2}{*}{$\mathrm{CV}(\%)$} \\
\hline & 22 & 26 & 30 & 34 & 38 & \\
\hline Peso inicial (g) & $0,63 a$ & $0,63 a$ & $0,63 a$ & $0,63 a$ & $0,63 a$ & $2,1^{\text {ns }}$ \\
\hline Peso final $^{1}$ (g) & $3,40 \mathrm{~b}$ & $4,06 b$ & $4,12 b$ & $5,35 a$ & $5,49 a$ & $20,9 *$ \\
\hline Ganho de peso ${ }^{2}(\mathrm{~g})$ & $2,80 \mathrm{~b}$ & $3,47 b$ & $3,52 b$ & $4,75 a$ & $4,87 a$ & $24,1^{*}$ \\
\hline Conversão alimentar aparente ${ }^{3}$ & $2,83 b$ & $2,57 b$ & $2,29 b$ & $1,69 \mathrm{a}$ & $1,88 \mathrm{a}$ & $27,67 *$ \\
\hline Sobrevivência (\%) & $100,00 a$ & $92,00 a$ & $84,00 a$ & $96,00 \mathrm{a}$ & $96,00 \mathrm{a}$ & $16,2^{*}$ \\
\hline
\end{tabular}

* Significativo a 5\% de probabilidade pelo teste de Scott Knot.

alimentar aparente, demonstrando que estes níveis não atendem a exigência dos peixes. Resposta semelhante, em que acima de um determinado nível protéico não ocorre melhora na conversão alimentar aparente, foi observada por BOMFIM et al. (2005) para alevinos de curimbatá (P. affins), SIDDIQUI et al. (1988) e FURUYA et al. (2000) para a tilápia do Nilo (O. niloticus) e SANTIAGO \& REYES (1991) para a carpa cabeça grande (Aristichthys nobilis). Resultados semelhantes, em que o aumento do teor protéico na dieta proporcionou melhores resultados de conversão alimentar aparente, foram observados por ELDAHHAR \& LOVELL (1995) para a tilápia mossambique (Oreochromis mossambicus), SÁ \& FRACALOSSI (2002) para a piracanjuba (B. orbigyanus), FERNANDES et al. (2000) e FERNANDES et al. (2001) para juvenis de pacu (P. mesopotamicus) e SAMPAIO et al. (2000) para o tucunaré (Cicla sp.). Por outro lado, há casos em que o nível de proteína bruta na dieta não influenciou os resultados de conversão alimentar aparente, conforme verificado por VIDAL JR. (1998) para juvenis de tambaqui (C. macropomum), FURUYA et al. (1996) para alevinos de tilápia do Nilo (O. niloticus) e SIGNOR et al. (2004) para alevinos de jundiá ( $\boldsymbol{R}$. quelen).

Não foi observada influência do nível protéico sobre a sobrevivência dos animais. Estes resultados se assemelham aos observados por SIGNOR et al. (2004) para alevinos de jundiá (R. quelen) e FURUYA et al. (2000) para alevinos de tilápia do Nilo (O. niloticus) submetidos a dietas contendo diferentes níveis protéicos. Por outro lado, HAYASHI et al. (2002) observaram efeito linear inversamente proporcional para a sobrevivência de larvas de tilápia do Nilo ( $\boldsymbol{O}$. niloticus), conforme o aumento do nível protéico na dieta.

Os aminoácidos da dieta são utilizados para a síntese protéica ou para os compostos nitrogenados essenciais para o metabolismo durante o processo de crescimento e o processo de reprodução dos peixes
(MILLWARD, 1989), sendo que a metionina, a cistina e a lisina são essenciais para o crescimento dos peixes. No presente experimento, o teor destes aminoácidos aumenta conforme a elevação do nível protéico da dieta. Correlacionando os resultados de desempenho com os teores calculados de metionina, cistina e lisina, foi observado que acima de $0,64 \%$ de metionina, $0,69 \%$ de cistina e 2,09\% de lisina, correspondente a 1,88, 2,04 e 6,16\% da proteína, respectivamente, não houve diferença no desempenho. Porém, dietas com $0,58 \%$ de metionina, $0,65 \%$ de cistina e $1,83 \%$ de lisina, correspondendo a 1,95, 2,16 e 6,11\% da proteína da dieta ou níveis inferiores, não apresentaram resultados satisfatórios de desempenho em comparação com as demais dietas.

O consumo de rações pelos peixes é regulado principalmente pela concentração energética da dieta (LOVELL, 1989). A elevada disponibilidade de energia em rações resulta na baixa ingestão de proteína e conseqüentemente de nutrientes essenciais (CHOU \& SHIAU, 1996; PEZZATO et al., 2001; HAYASHI et al., 2002). Este fato foi observado no presente trabalho, pois os melhores resultados de desempenho foram encontrados para as dietas com 8,42kcal de energia digestível $\mathrm{g}^{-1}$ de proteína bruta, não diferindo de 9,41 e $10,68 \mathrm{kcal} \mathrm{g}^{-1}$. Porém, os animais que receberam dietas com 22 e $26 \%$ de proteína bruta, correspondendo a 14,54 e 12,31 kcal de energia digestível $\mathrm{g}^{-1}$ de proteína bruta, não apresentaram desempenho eficiente em comparação com os demais tratamentos.

A relação energia:proteína está diretamente relacionada ao hábito alimentar dos animais, pois peixes carnívoros requerem menor relação nas rações. Estas espécies aproveitam mais eficientemente a energia proveniente de gorduras em comparação com os peixes herbívoros, que aproveitam eficientemente os carboidratos como fonte energética (CHO \& KAUSHIK, 1990). A melhor relação energia:proteína para a piracanjuba (B. orbynyanus), segundo SÁ \& FRACALOSSI (2002), é de 10,40kcal de energia 
metabolizável $\mathrm{g}^{-1}$ de proteína bruta, para o curimbatá (P. affins), é de 10,36kcal de energia digestível $\mathrm{g}^{-1} \mathrm{de}$ proteína bruta, segundo BONFIM et al. (2005). A melhor relação energia digestível:proteína bruta para alevinos de peixe-rei é de 6,29-6,86kcal de energia digestível $\mathrm{g}^{-1}$ de proteína bruta (PIEDRAS et al., 2004) e a relação ideal para alevinos de black bass (Micropterus salmoides) fica na faixa de 7,78-8,83kcal de energia digestível $\mathrm{g}^{-1}$ de proteína bruta, como observada por CYRINO et al. (2000), sendo que, para alevinos de tucunaré, a exigência é de $9 \mathrm{kcal}$ de energia digestível $\mathrm{g}^{-1}$ de proteína bruta, que foi verificada por SAMPAIO et al. (2000).

Com relação à composição química dos peixes, foi observado efeito linear inversamente proporcional ao nível protéico das rações para a matéria mineral e efeito linear diretamente proporcional para a umidade. A deposição protéica e a eficiência alimentar não foram influenciadas pelo nível protéico da dieta (Tabela 3).

A diminuição no teor de matéria mineral dos peixes com o aumento dos níveis de proteína bruta pode ser explicada devido ao fato que, nas rações com menores teores de proteína bruta, houve uma maior inclusão de fosfato bicálcico (Tabela 1). Esta fonte de mineral pode apresentar maior disponibilidade de fósforo, resultando em maior deposição de minerais em comparação com os alimentos de origem vegetal, por apresentaram baixos níveis de fósforo e baixa disponibilidade desse mineral (FURUYA et al., 2001). Estes alimentos contêm de 0,5 a 6,0\% de ácido fítico e, portanto, de 50 a $90 \%$ de seu total de fósforo na forma de fitato (NOLAN \& DUFFIN, 1987), que é capaz de se complexar com cátions, proteínas, lipídeos e amido, tornando grande parte destes nutrientes não digestíveis para os peixes, em razão da ausência da enzima endógena fitase (VIELMA et al., 1998).

Os peixes alimentados com dietas contendo baixos teores de proteína apresentaram menores teores de umidade em comparação com os outros tratamentos. Este resultado é semelhante aos resultados observados por SERAFINI (2003) e COTAN et al. (2006) para alevinos de tambiú e BOMFIM et al. (2005) para alevinos de curimbatá (P. affins). Geralmente rações com baixos teores de proteína apresentam maior relação energia digestível:proteína bruta, acarretando maior deposição de gordura. Em peixes, quanto maior o teor de gordura, menor o teor de umidade (OGAWA \& MAIA, 1999), pois a gordura é armazenada em estado cristalino com baixa umidade. Por outro lado, SÁ \& FRACALOSSI (2002) observaram aumento da concentração de proteína bruta corporal e diminuição da concentração de lipídeos totais com o aumento da concentração protéica na dieta de piracanjuba (B. orbignyanus).

Não foi observada $(\mathrm{P}<0,05)$ variação na taxa de eficiência protéica dos peixes. Resultados estes contrários aos observados por MEYER \& FRACALOSSI (2005) para o jundiá (R. quelen), em que os autores observaram que há aumento do nível protéico na dieta na medida em que a taxa de eficiência protéica é aumentada. Por outro lado, tendências opostas foram observadas por VIDAL JR. et al. (1998) para alevinos de tambaqui (C. macropomum). Resultados ainda diferentes foram observados por SIDDIQUI et al. (1988), em experimento com pós-larvas e alevinos de tilápia (Oreochromis niloticus), os quais verificaram que, com o aumento do nível de proteína bruta até 50\%, ocorreu redução nos valores da taxa de eficiência protéica e a partir desse nível essa torna a se elevar.

A alimentação com adequado teor protéico e balanço aminoacídico adequado é fundamental para proporcionar melhor desempenho dos peixes, pois os aminoácidos que não forem utilizados para síntese protéica serão deaminados e servirão como fonte de energia ou serão convertidos em gordura e poderão resultar em maior poluição ambiental.

Tabela 3 - Composição química da carcaça de alevinos de piavuçu (L. macrocephalus) alimentados com dietas contendo diferentes níveis de proteína bruta (materia natural).

\begin{tabular}{|c|c|c|c|c|c|c|c|}
\hline \multirow{2}{*}{ Parâmetros } & \multirow{2}{*}{ Inicial } & \multicolumn{5}{|c|}{-------------------------Níveis de proteína bruta (\%)------------------------- } & \multirow{2}{*}{ CV (\%) } \\
\hline & & 22 & 26 & 30 & 34 & 38 & \\
\hline Umidade $^{1}$ & 79,36 & 72,05 & 72,85 & 74,14 & 74,77 & 76,25 & 1,4 \\
\hline Proteína bruta & 13,64 & $14,05 a$ & $14,13 a$ & $14,10 \mathrm{a}$ & $14,11 \mathrm{a}$ & $14,32 \mathrm{a}$ & 4,5 \\
\hline Matéria mineral $^{2}$ & 3,66 & 3,58 & 3,29 & 3,23 & 2,96 & 2,74 & 6,9 \\
\hline Eficiência protéica & - & $3,11 \mathrm{a}$ & $3,04 a$ & $3,27 \mathrm{a}$ & $2,75 a$ & $3,27 \mathrm{a}$ & 25,1 \\
\hline
\end{tabular}

* Significativo a 5\% de probabilidade pelo teste de Scott Knot.

1 efeito linear $\left(Y=66,2847-0,5866 X, r^{2}=0,99\right)$.

2 efeito linear $\left(\mathrm{Y}=4,6676-0,0501 \mathrm{X}, \mathrm{r}^{2}=0,95\right)$. 


\section{CONCLUSÕES}

A utilização de rações com 34\% de proteína bruta na alimentação de alevinos de piavuçu ( $\boldsymbol{L}$. macrocephalus) permite bom desempenho dos animais.

\section{REFERÊNCIAS}

AOAC. ASSOCIATION OF OFFICIAL ANALYTICAL CHEMISTS. Oficial methods of analysis of association of official analytical chemists. 17.ed. Arlington, 2000. V.1 e .2.

BOMFIM, M.A.D. et al. Proteína bruta e energia digestível em dietas para alevinos de curimbatá (Prochilodus affins). Revista Brasileira de Zootecnia, v.34, n.6, p.1795-1806, 2005.

BOSCOLO, W.R. et al. Digestibilidade aparente da energia e nutrientes de alimentos convencionais e alternativos para a tilápia do Nilo (Oreochromis niloticus, L.). Revista Brasileira de Zootecnia, v.13, n.2, p.539-545, 2002.

BOSCOLO, W.R. et al. Farinha de resíduo da filetagem de tilápia em rações para alevinos de piavuçú, (Leporinus macrocephalus). Revista Brasileira de Zootecnia, v.34, n.6, p.1819-1827, 2005.

BOYD, C. Water quality in ponds for aquaculture. Alabama: Birminghaum, 1990. 482p.

BROWN, P.B., ROBINSON, E.H. Comparison of practical catfish feeds containing 26 or $30 \%$ protein. Progressive FishCulturist, v.51, p.149-151, 1989.

CHO, C.Y.; KAUSHIK, S.J. Effects of protein intake on metabolizable and net energy values of fish diets. In: COWEY, C.B. et al. (Eds.). Nutrition and feeding in fish. London: Academic, 1985. p.95-117.

CHOU, B.S., SHIAU, S.Y. Optimal dietary lipid level for growth of juvenile hybrid tilapia, Oreochromis niloticus x Oreochromis aureus. Aquaculture, v.143, n.2, p.185-195, 1996.

CYRINO, J.E.P. et al. Retenção de proteína e energia em juvenis de "black bass" Micropterus salmoides. Scientia Agrícola, v.57, n.4, p.609-616, 2000.

COTAN, J.L.V. et al. Níveis de energia digestível e proteína bruta em rações para alevinos de lambari tambiú. Revista Brasileira de Zootecnia, v.35, n.3, p.634-640, 2006.

El-DAHHAR, A.A.; LOVELL, R.T. Effect of protein to energy ratio in purified diets on growth performance, feed utilization and body composition of mossambique tilapia, (Oreochromis mossambicus) (Peters). Aquaculture Research, v.26, p.451457, 1995.

EL-SAYED, A.F.M. Alternative dietary protein sources for farmed tilapia, Oreochromis spp. Aquaculture, v.179, p.149168, 1999.

FERNANDES, J.B.K. et al. Fontes e níveis de proteína bruta em dietas para alevinos de pacu (Piaractus mesopotamicus). Revista Brasileira Zootecnia, v.29, n.3, p.646-653, 2000.
FERNANDES, J.B.K. et al. Fontes e níveis de proteína bruta em dietas para juvenis de pacu (Piaractus mesopotamicus). Revista Brasileira Zootecnia, v.30, n.3, p.617-626, 2001.

FURUYA, W.M. et al. Use of ideal protein concept for precision formulation of amino acids level in diets with and without dicalcium phosphate for juvenile Nile tilapia. Aquaculture Research, v.35, p.110-1116, 2004

FURUYA, W.M. et al. Exigência de proteína para alevino revertido de tilápia do Nilo (Oreochromis niloticus). Revista Brasileira Zootecnia, v.29, n.6, p.1912-1917, 2000.

FURUYA, W.M. et al. Exigência de proteína para machos revertidos de tilápia do Nilo (Oreochromis niloticus L.), na fase juvenil. Revista Unimar, v.18, n.2, p.307-319, 1996.

FURUYA, W.M. et al. Fitase na alimentação da Tilápia do Nilo (Oreochromis niloticus). Desempenho e digestibilidade. Revista Brasileira de Zootecnia, v.30 n.3, p.924-929, 2001.

GONÇALVES, G.S.; FURUYA, W.M. Digestibilidade aparente de alimentos pelo piavuçu, (Leporinus macrocephalus). Acta Scientiarum. v.26, n.2, p.165-169, 2004.

HAYASHI, C. et al. Exigência de proteína digestivel para larvas de tilápia do Nilo (Oreochromis niloticus), durante a reversão sexual. Revista Brasileira de Zootecnia, v.31, n.2, p.823828, 2002.

HAYASHI, C. et al. Uso de diferentes graus de moagem dos ingredientes em dietas para a tilápia do Nilo (Oreochromis niloticus, L.) na fase de crescimento. Acta Scientiarum, v.21, n.3, p.733-737, 1999.

LENHINGER, A.L. et al. Princípios de bioquímica. São Paulo: Sarvier, 1995. 839p.

LOVELL, T. Nutiriton and feeding of fish. New York:Van Nostrand Reinhold, 1988. 260p.

MEIJER, A.J. et al. Nitrogen metabolism and ornitine cycle function. Phisiological Reviews. v.70, n.3, p.701-748, 1990.

MEYER, G.; FRACALOSSI, D.N. Estimation of jundia (Rhamdia quelen) dietary amino acid requeriments base don muscle amino acid composition. Scientia Agrícola, v.62, n.4, p.401-405, 2005.

MILLWARD, D.J. The nutritional regulation of muscle growth and protein turnover. Aquaculture, v.79, p.1-58, 1989.

NOLAN, K.B.; DUFFIN P.A. Effects of phytase on mineral bioavailability, in vitro studies on $\mathrm{Mg} 2+, \mathrm{Ca} 2+, \mathrm{Fe} 2+, \mathrm{Cu} 2+$ and Zn2+ (also Cd2+) solubility in the presence of phytase. Journal Science Food Agriculture, v.40, p.79-85, 1987.

OGAWA, M.; MAIA, E.L. Manual da pesca: ciência e tecnologia do pescado. São Paulo: Varela, 1999. 430p.

PEZZATO, L.D. et al. Nutrição e alimentação de peixes. Viçosa: CPT, 2001. 72p.

PIEDRAS, S.R.N.et al. Efeitos de diferentes níveis de proteína bruta e de energia digestível na dieta sobre o desempenho de alevinos de peixe-rei. Revista brasileira de Agrociência, v.10, n.1, p.97-101, 2004. 
ROBINSON, E.H., WILSON, R.P. Nutrition and feeding. In: TUCKER, C.S. (Ed.). Channel catfish culture. New York: Elsevier, 1985. p.323-404.

SÁ, M.V.C.; FRACALOSSI, D.M. Exigência protéica e relação energia/proteína para alevinos de piracanjuba (Brycon orbignyanus). Revista Brasileira de Zootecnia., v.31, n.1, p.1-10, 2002.

SAMPAIO, A.M.B. et al. Relação energia:proteína na nutrição do tucunaré. Scientia Agrícola, v.57, n.2, p.213-219, 2000.

SANTIAGO, C.B.; REYES, O.F. Optimum dietary protein level for growth of bighead carp (Aristichthys nobilis) fry in a static water system. Aquaculture, v.93, p.155-165, 1991.

SERAFINI, M.A. Níveis de proteína em dietas de lambari tambiú dos 0,7 aos 4,8 gramas de peso. 2003. $25 f$. Dissertação (Mestrado em Zootecnia) - Universidade Federal de Viçosa.

SIDDIQUI, A.Q. et al. Effects of dietary protein levels and protein utilization in fry and young nile tilapia, (Oreochromis niloticus). Aquaculture, v.70, p.63-73, 1988.
SIGNOR, A. et al. Exigência de proteína bruta para alevinos de jundiá (Rhamdia quelen). Varia Scientia, v.4, n.1, p.79-89, 2004.

SILVA, S.S.; ANDERSON, T.A. Fish nutrition inaquaculture. London: Chapman Hall. 1995. 319p.

SOARES, C.M. et al. Substituição parcial e total da proteína do farelo de soja pela proteína do farelo de canola na alimentação de alevinos de piavuçu (Leporinus macrocephalus, L.). Revista Brasileira de Zootecnia, v.29, n.1, p.15-22, 2000.

UNIVERSIDADE FEDERAL DE VICCOSA. UFV. SAEG Sistema para análises estatísticas e genéticas. Versão 7.1. Viçosa, MG, 1997. . 150p. (Manual do usuário).

VIDAL JÚNIOR, M.V. et al. Níveis de proteína bruta para tambaqui (Colossoma macropomun), na fase de 30 a 250 gramas. 1. Desempenho dos tambaquis 1. Revista Brasileira de Zootecnia, v.27, n.3, p.421-426, 1998.

VIELMA, J. et al. Effects of dietary phytase and cholecalciferol on phosphorus bioavailability in rainbow trout (Oncorhynchus mykiss). Aquaculture, v.63, n.3/4, p.309-323, 1998 